\title{
Full-scale experiments to measure the effect of crosscut height on recovery in sublevel cave mines
}

\author{
AD Campbell Beck Engineering, Australia
}

\begin{abstract}
A major disadvantage of the sublevel cave (SLC) mining method is the potential for substantial dilution and ore loss. Scale-model experiments demonstrate that gravity flow and recovery in SLC mines is affected by crosscut geometry. Several authors also suggest that crosscut height affects the digging depth of loading equipment and therefore influences recovery, particularly from the back of a blasted ring. However, specifically designed full-scale experiments that directly compare the effect of different crosscut heights on recovery have not been published to date.

This paper details the results of experiments conducted in an operating SLC mine to measure the effect of crosscut height on recovery and depth of draw. Two trial programs, each consisting of six blast rings, and each with approximately 285 electronic cave markers, were used to measure recovery in real time. One trial measured recovery for the standard $5 \mathrm{~m}$ crosscut height and the other for a crosscut height of $4 \mathrm{~m}$; the smallest practical dimension for loaders used at the mine. The effect of reducing the crosscut height is a reduction in the distance a muck pile extends from the brow. The literature suggests that a shorter muck pile will enable loading equipment to dig deeper relative to the drawpoint brow. This was hypothesised to increase ore recovery from the back of the blast ring in a mining method in which shallow draw is common.

The experimental program showed that reducing the crosscut height did not achieve the desired effect of improving primary recovery. It is proposed that drawpoint flow is controlled by the outflow depth at the drawpoint brow rather than the dig depth or length of the muck pile under the test conditions. Observations identified that the bucket of the loader did not penetrate the muck pile beyond the drawpoint brow, despite the crosscut height being reduced as far as practical. The experimental results do not justify SLC mines reducing the crosscut height to increase ore recovery. In terms of mine design guidelines, it is recommended that crosscut height be based solely on geotechnical, operational and equipment requirements.
\end{abstract}

An accompanying paper in the proceedings (Campbell 2018) details the results of experiments conducted using different ring burdens and explosive densities to determine the effect on fragmentation and recovery.

Keywords: gravity flow, mine design, ore recovery, sublevel caving

\section{Introduction}

The design of cave mines is known to affect ore recovery, dilution entry, pillar stability and overall viability of the operation. Despite the importance of mine design for operational success and profitability of these mines, many aspects of cave mine design rely on experience, rules of thumb developed from model-scale experiments and, more recently, numerical modelling. However, relatively few full-scale experiments have been conducted to measure the effect of different mine design parameters at full-scale. As a result, engineers designing caving mines rely on general guidelines. Current shortcomings are not due to a lack of interest or technical curiosity, but the expense, time and operational difficulties when conducting full-scale experiments in large, operating caving mines.

This paper details full-scale experiments conducted at the Ernest Henry mine (EHM) to measure the effect of crosscut height on ore recovery and determine if improvements to recovery could be made by reducing the crosscut height. This follows design recommendations made by Just (1972), Trotter and Goddard (1981), Page \& Bull (2001), Power (2004) and Dunstan and Power (2011), which have remained untested at full scale 
until experiments conducted at EHM. A series of experiments to quantify the effect of ring burden and explosive density on fragmentation and ore recovery was also carried out at the EHM sublevel cave (SLC). The results of these experiments are detailed in an accompanying paper at this conference (Campbell 2018).

\section{$1.1 \quad$ Sublevel caving}

Sublevel caving has the disadvantage of relatively high levels of dilution and ore loss compared with other mining methods (Brunton et al. 2010; Bull \& Page 2000; Kvapil 1998; Wimmer 2010; Zhang 2004). Sublevel cave mine design must consider stability and equipment requirements while aiming to maximise ore recovery and minimise dilution and waste extraction (Wimmer 2012). Significant research has been conducted since the 1950s to measure gravity flow in SLC mines. However, gravity flow is complex because of the large number of variables such as blasting, fragmentation, rock mass conditions and mine design. Gaps in the current state of knowledge remain because of the small number of full-scale recovery experiments conducted in operating mines to measure the effect of blast design and mine design parameters on recovery. Various full-scale recovery experiments have been conducted to date which have focused on developing a fundamental understanding of material flow. No specifically designed experiments have measured the effect of crosscut height on ore recovery and gravity flow mechanics to date.

\subsection{Gravity flow theory and the effect of crosscut height}

Scale models have been used to measure the effect of different material properties (particle size, friction angle, density and compaction), sublevel and crosscut spacing, crosscut width and draw control practices. Experimental results provided early researchers with an understanding of gravity flow but were not capable of accurately simulating full-scale gravity flow behaviour (Brunton 2009; Power 2004; Wimmer 2010). Full-scale experiments in operating mines were conducted to further understand recovery in SLC mines as the scale of mining operations increased significantly over time (Gustafsson 1998; Hollins \& Tucker 2004; Kosowan 1999; Power 2004; Quinteiro et al. 2001). Marker recovery was used to interpret ore recovery and draw zone evolution for each test ring, and characterised gravity flow into three categories: standard, shallow and deviatory (Power 2004). Interpreted draw zone geometry from the Ridgeway SLC found that the depth of the flow zone during primary recovery was often less than the $2.6 \mathrm{~m}$ ring spacing. It was also speculated that overall recovery could be increased if more material from the back of the blasted ring could be recovered (Power 2004). This recommendation follows those of previous researchers including Just (1972) and Trotter and Goddard (1981).

Sublevel cave mining is a multi-level recovery system (Dunstan \& Power 2011). Recovery of material from a blasted ring on the same level is known as primary recovery. Remaining portions of a blasted ring may be recovered on lower levels as secondary or tertiary recovery and so on. However, ore recovered on lower levels is more prone to dilution as it mixes with low-grade and waste material in the cave. It is more favourable to maximise primary ore recovery for this reason.

There are three main regions of a blasted ring that have low primary recovery and can result in ore loss. These are:

1. The back of the ring where the depth of the extraction zone is less than the ring burden.

2. The ore buried behind the muck pile that cannot be reached by the load-haul-dump (LHD) unit bucket as shown in Figure 1.

3. The sides of the ring where the width of the blasted ring (around $15 \mathrm{~m}$ ) is wider than the draw zone geometry (generally 9-12 m); crosscuts are offset from each other between sublevels so that the sides of the ring not recovered as primary recovery can be recovered as secondary recovery. 


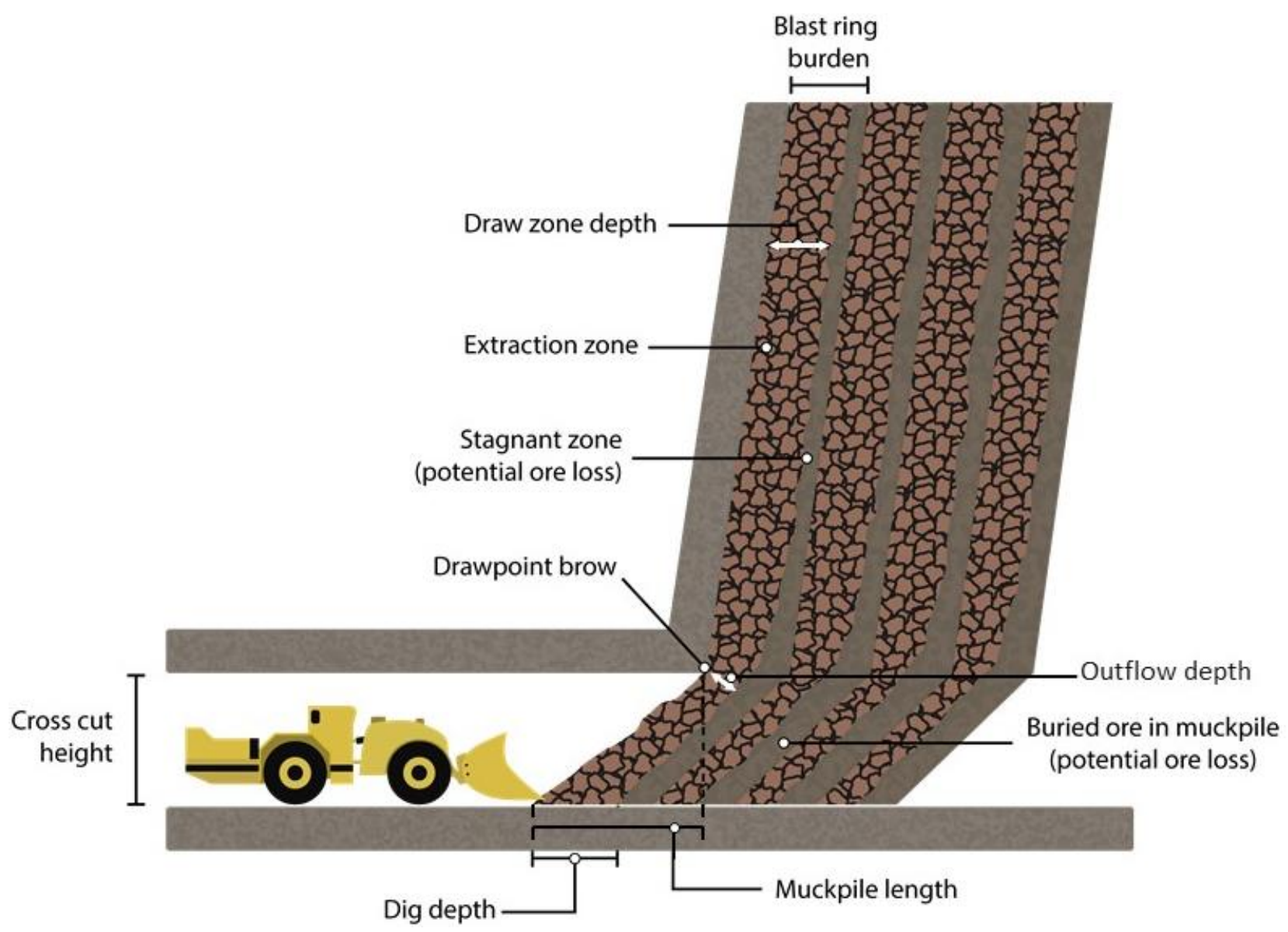

Figure 1 Cross-section of the extraction zone and stagnant zones over four consecutive blast rings (modified from Just 1972)

Following a series of scale-model experiments and observations at Mount Isa Mines, Just (1972) stated that it is advisable to minimise crosscut height to minimise potential ore loss in SLC mines. Just (1972) outlined two methods to increase primary ore recovery. The first is to decrease the crosscut height to decrease the length of the muck pile. As the muck pile length is reduced, the LHD dig depth is increased relative to the drawpoint brow resulting in greater ability to recover material from the back of the ring. Dunstan and Power (2011), Power (2004) and Trotter and Goddard (1981) all outlined similar design recommendations and these suggestions form the basis for the full-scale experiments outlined in this paper. The second method to improve primary recovery is to match the depth of draw to the ring burden. This approach is further justified following the results of the cave marker experiments conducted by Power (2004), which demonstrated that shallow draw was common and recovery from the back of a ring was considerably less than at the front of the ring (closer to the drawpoint). Despite the potential for significant economic improvement by increasing ore recovery and reducing ore loss and dilution in SLC mines, a full-scale experimental study to determine if crosscut height affects ore recovery has not been published to date. Full-scale experiments were conducted at EHM to quantify the effect of crosscut height on recovery.

\section{Experimental design}

Ernest Henry mine is an SLC operation located near Cloncurry in northwestern Queensland. The underground copper-gold mine is below a closed open pit operation and targets the orebody down dip to a depth of approximately $1 \mathrm{~km}$ as shown in Figure 2. Additional details regarding the mine can be found in Campbell and Power (2017). 


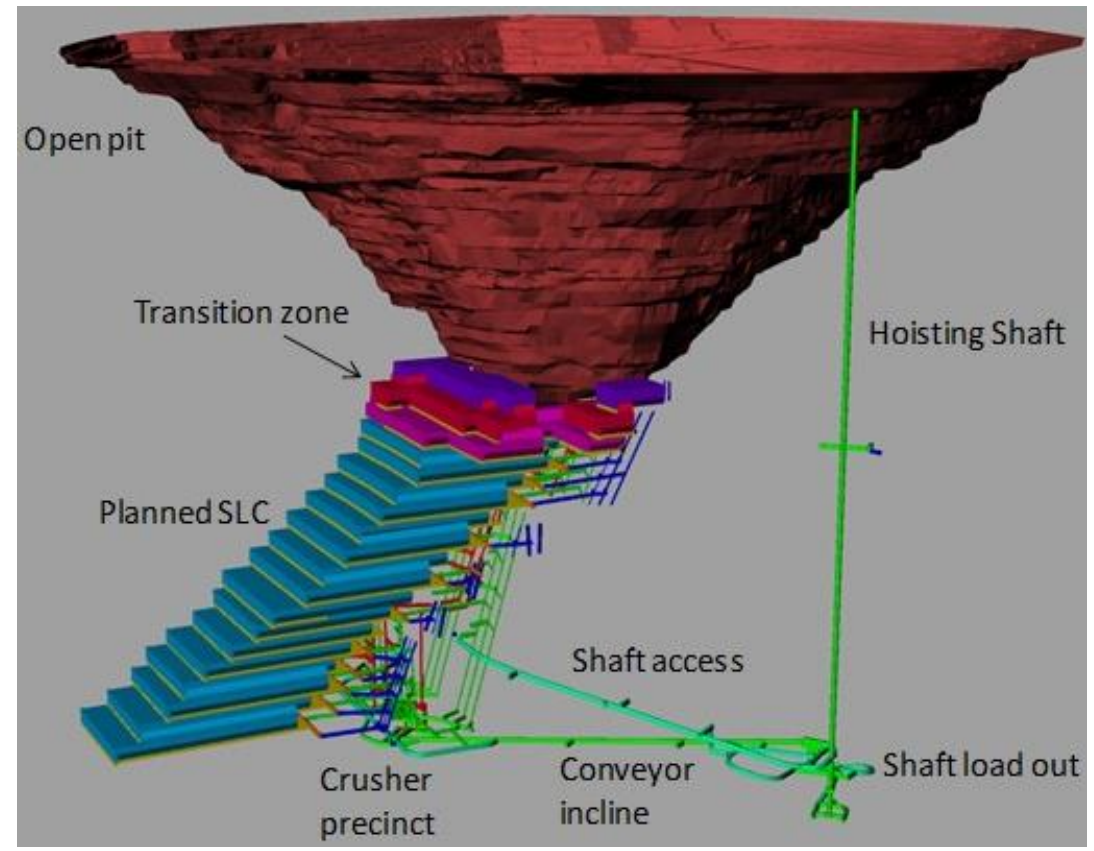

Figure 2 Isometric view of the mine including the open pit and underground mine design including the sublevel cave and underground infrastructure

The SLC has $25 \mathrm{~m}$ sublevel spacing and $15 \mathrm{~m}$ crosscut spacing (centre to centre). Production crosscuts are $6 \mathrm{~m}$ wide and $5 \mathrm{~m}$ high. Production rings are blasted using an eight-hole fan pattern of $102 \mathrm{~mm}$ holes with ring spacing of $2.6 \mathrm{~m}$ as shown in Figure 3 and detailed in Table 1. Blasting is conducted using non-electric detonators and Titan 7000i emulsion with a density of $1.1 \mathrm{~g} / \mathrm{cc}$ and a 28 day approved sleep time. Each ring has approximately 165 drill metres and contains an average of 2,850 t of rock. Blastholes are double primed on the same delay at the centre and toe of the hole. Blastholes are initiated from the centre outwards.

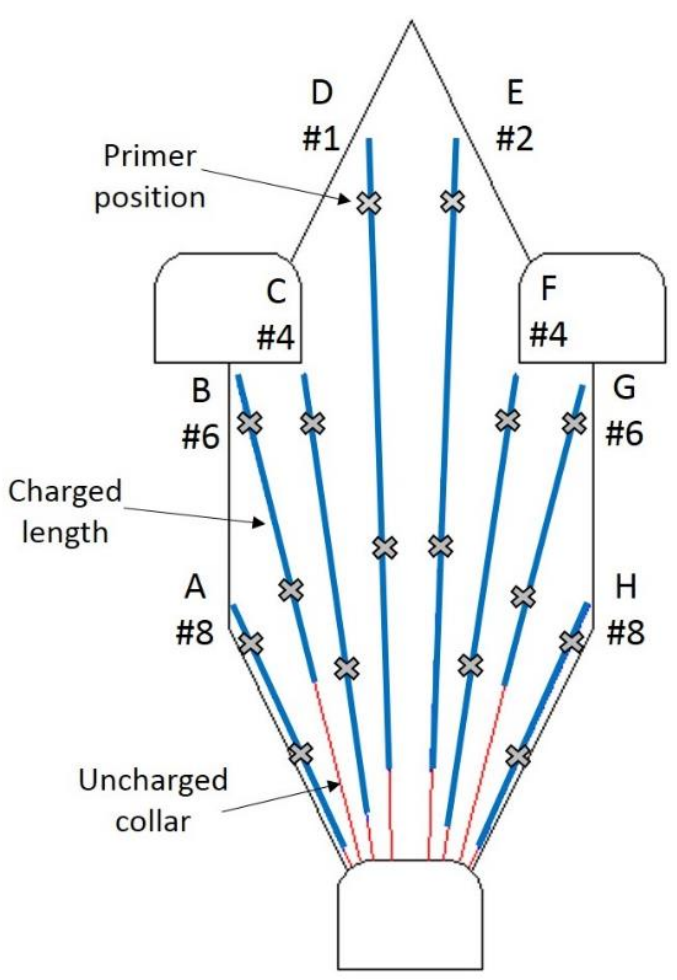

Figure 3 Generic blast design used in the marker recovery experiments. Charged hole length shown by the (thicker) blue line and uncharged collars in red. Crosses indicate primer position. The hole number and delay number are also shown 
Table 1 Ernest Henry mine drill and blast parameters

\begin{tabular}{ll}
\hline Parameter & Value \\
\hline Sublevel spacing & $25 \mathrm{~m}$ \\
Production crosscut width & $6 \mathrm{~m}$ \\
Production crosscut height & $5 \mathrm{~m}$ \\
Pillar width & $9 \mathrm{~m}$ \\
Production ring tonnage (average) & $2,850 \mathrm{t}$ \\
Blasthole diameter & $102 \mathrm{~mm}$ \\
Blastholes per ring & 8 \\
Drilled metres per blast ring & $165 \mathrm{~m}$ \\
Ring burden & $2.6 \mathrm{~m}$ \\
Toe spacing & $2.8-3.2 \mathrm{~m}$ \\
Spacing-to-burden ratio & $1.1-1.2$ \\
Explosive type & Titan 7000i \\
Explosive density & $1.1 \mathrm{~g} / \mathrm{cc}$ \\
Powder factor & 0.4 \\
\hline
\end{tabular}

Blast rings are designed with uncharged collars of variable length to prevent damage to the brow of the ring. Up to three rings are pre-charged ahead of the cave front in each crosscut, which removes the need to access the brow for charging purposes, improves operator safety and increases productivity.

Quality assurance, including collar position, hole deviation, explosive density and blast performance was measured during the experiments. No significant deviations from routine monitoring results were identified during the trials. The full-scale experiments were conducted in two nearby production areas of almost identical geological and mining conditions. Each experiment involved three production rings in two neighbouring production crosscuts (i.e. six test rings per experiment). In one experiment, the crosscut floor was built up by $1 \mathrm{~m}$ to reduce the crosscut height by $20 \%$ (from 5 to $4 \mathrm{~m}$ ) as shown in Figures 4 and 5 . For practicality reasons, the floor was built up for $30 \mathrm{~m}$ back from the drawpoint with a gentle incline from the original floor to enable bogging to occur as normal and not reduce LHD speed or productivity. A $4 \mathrm{~m}$ crosscut height was the smallest practical dimension that could be achieved while still enabling an LHD to manoeuvre in the crosscut as required.

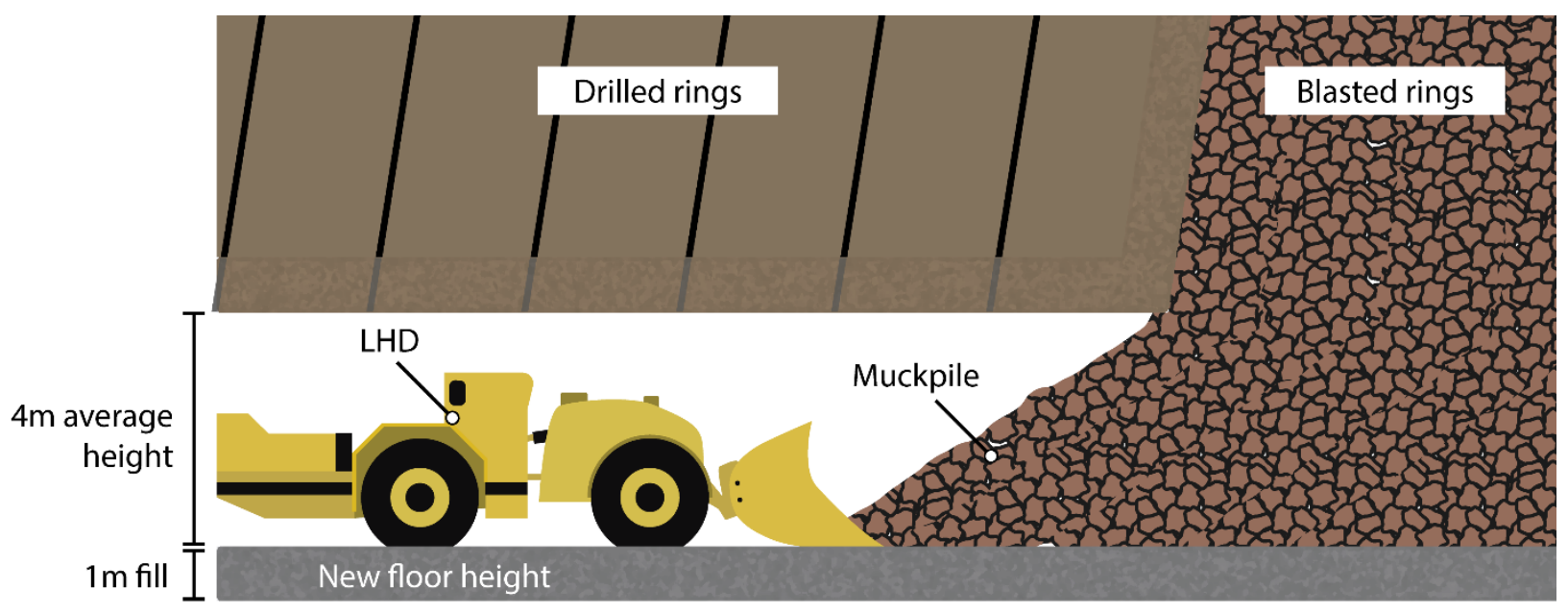

Figure 4 Experimental set-up for the reduced crosscut height trial program 


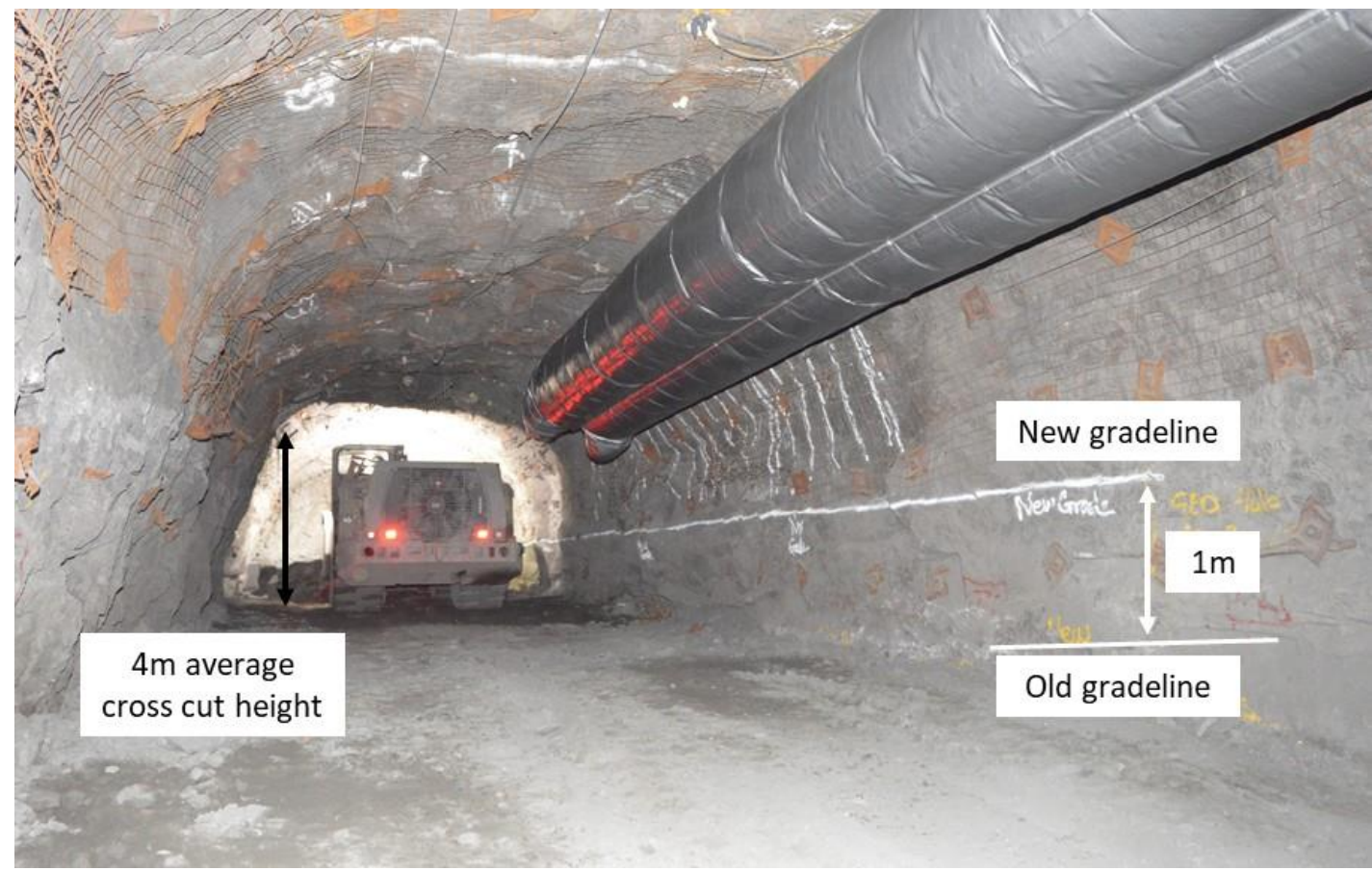

Figure 5 Load-haul-dump unit at a drawpoint with the reduced crosscut height experiment

Smart markers (Elexon Mining 2017) are blast-resistant radio frequency identification devices (RFIDs) which are installed in specifically drilled holes between blast rings to measure recovery. A dense array of approximately 285 electronic markers was installed in each blast ring to measure ore recovery and draw zone evolution in 3D (Figure 6). Almost 3,400 markers were installed in the two experiments (known as Trial Program 1 and 2). Each trial program included six production rings and the markers were installed in three rings of drilled holes evenly spaced at $0.65 \mathrm{~m}$ between the blast rings. The marker rings were drilled with an alternating pattern of 7-8-7 holes to distribute the markers as evenly as possible throughout the blasted material. The inter-hole spacing of the markers was $1.5 \mathrm{~m}$.

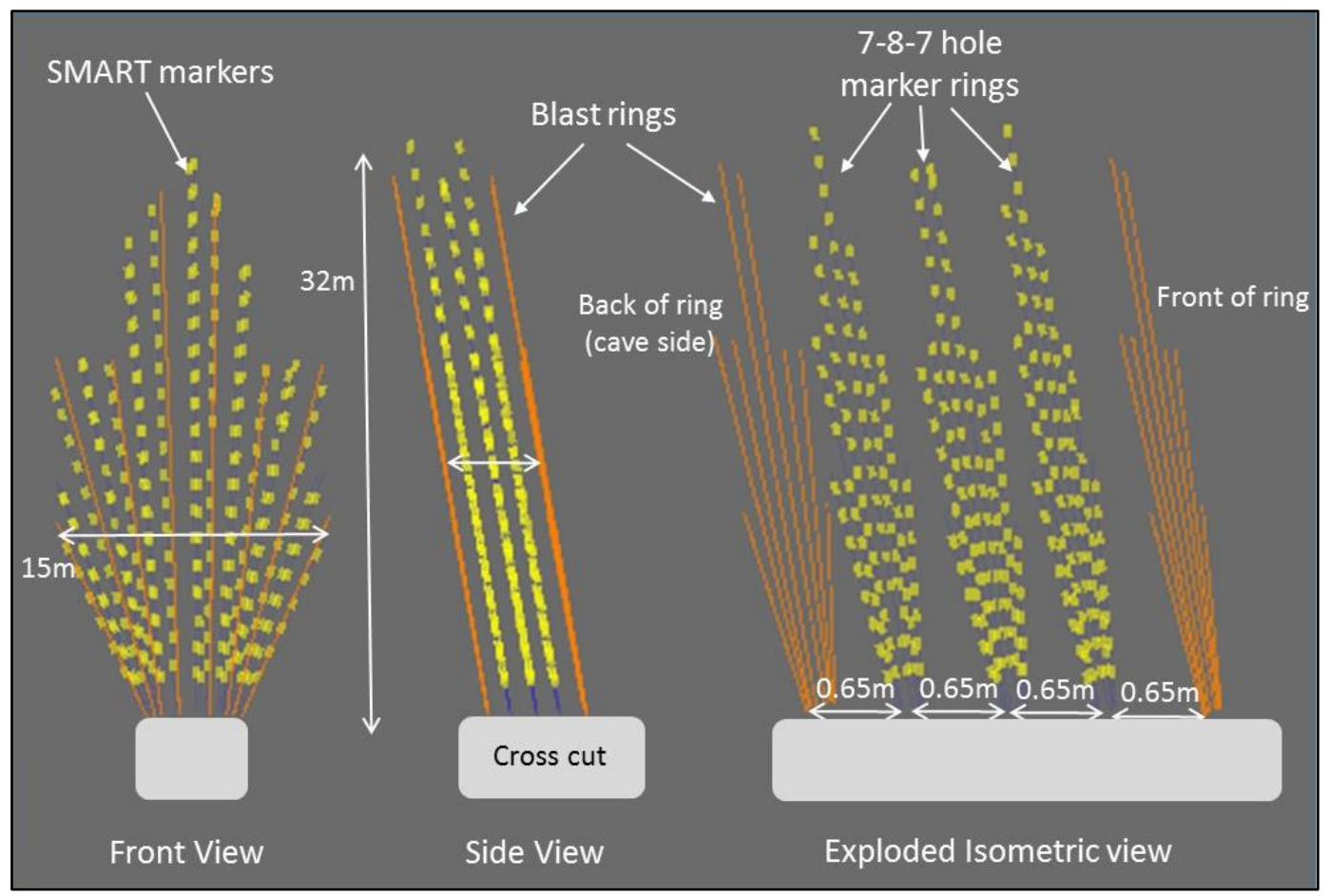

Figure 6 Layout of smart markers between production blast rings (not to scale) 
The layout of the markers was carefully selected to consider:

- Recommendations of other SLC marker recovery trials (Brunton 2009; Power 2004).

- Spatial distribution to measure the entire volume of blasted material.

- Measurement of the depth of recovery by using three marker planes. This was proven essential in marker recovery trials conducted by Power (2004).

- Sufficient marker density to ensure accurate recovery measurement and provide marker redundancy.

- Economic balance between a small number of detailed experiments and a large number of low-resolution experiments.

An example of the selected marker distribution in the seven-hole and eight-hole pattern is shown in Figure 7.

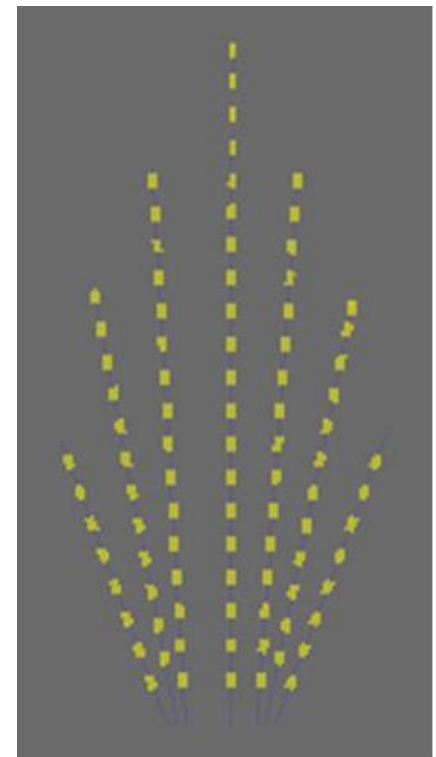

7 hole marker layout

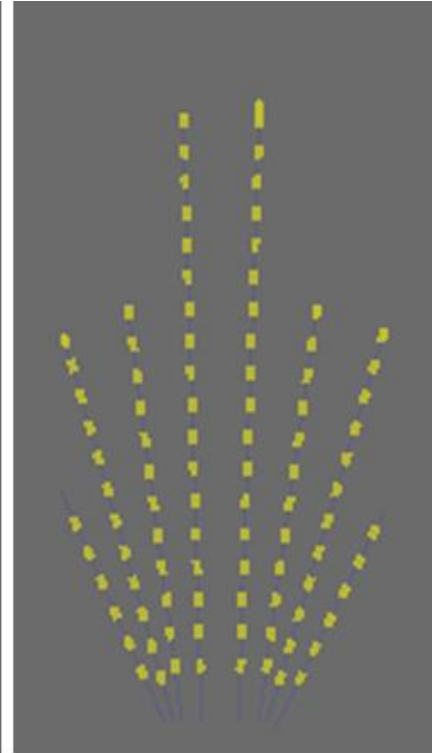

8 hole marker layout

Figure 7 Marker layout in the seven-hole and eight-hole drill rings

The markers were installed to a specified depth in each hole using a hose pusher mounted on a charging unit used for production charging (Figure 8). The markers were temporarily held in place by plastic barbs and then grouted in place soon after installation.

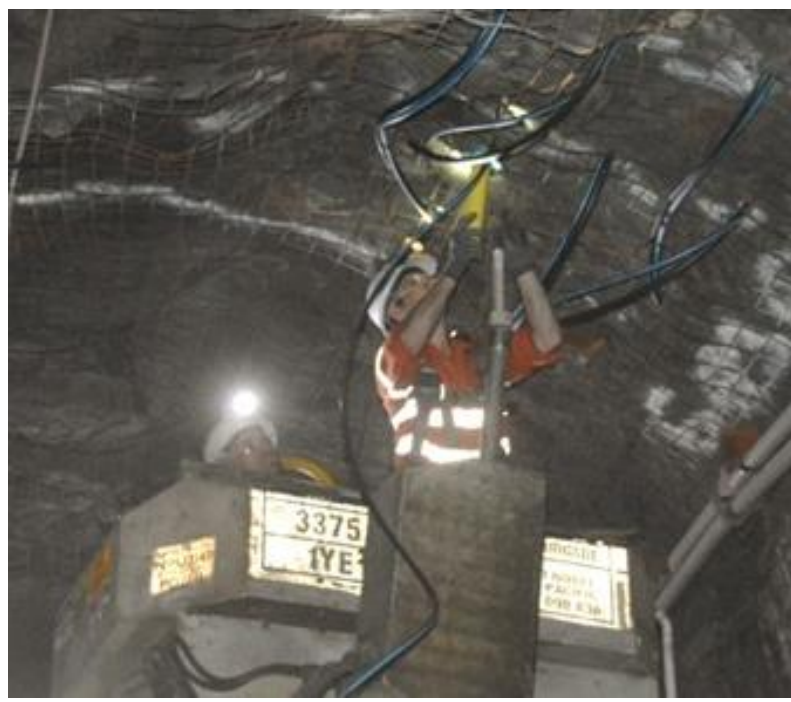

Figure 8 Installation of smart markers using a hose pusher mounted on an explosive charging unit 
The unique identification code of each marker is recorded by electronic readers mounted in the backs of each crosscut during ore extraction. A secondary reader was located at the orepass where the loaded material from the ring would be tipped into the grizzly and enter the orepass system and proceed to the crusher at the bottom of the mine. A secondary reader was deemed necessary to ensure all recovered markers were detected. The RFID signal from the antenna to the marker is powerful enough to detect markers through the broken rock of a loaded bucket. This enables real-time tracking of ore recovery as markers are recovered from the cave as shown in Figure 9. An example of a recovered marker grouted within a rock is shown in Figure 10. Marker detection is time stamped so the sequence marker recovery can be determined. Recovery information is then correlated with production records to track the tonnage interval when each marker was detected. Marker recovery data, in combination with underground observations, can then be used to interpret recovery as well as flow mechanisms occurring inside the blasted ring during extraction. The markers have a battery life of up to eight years and are detected as they are extracted over multiple sublevels.

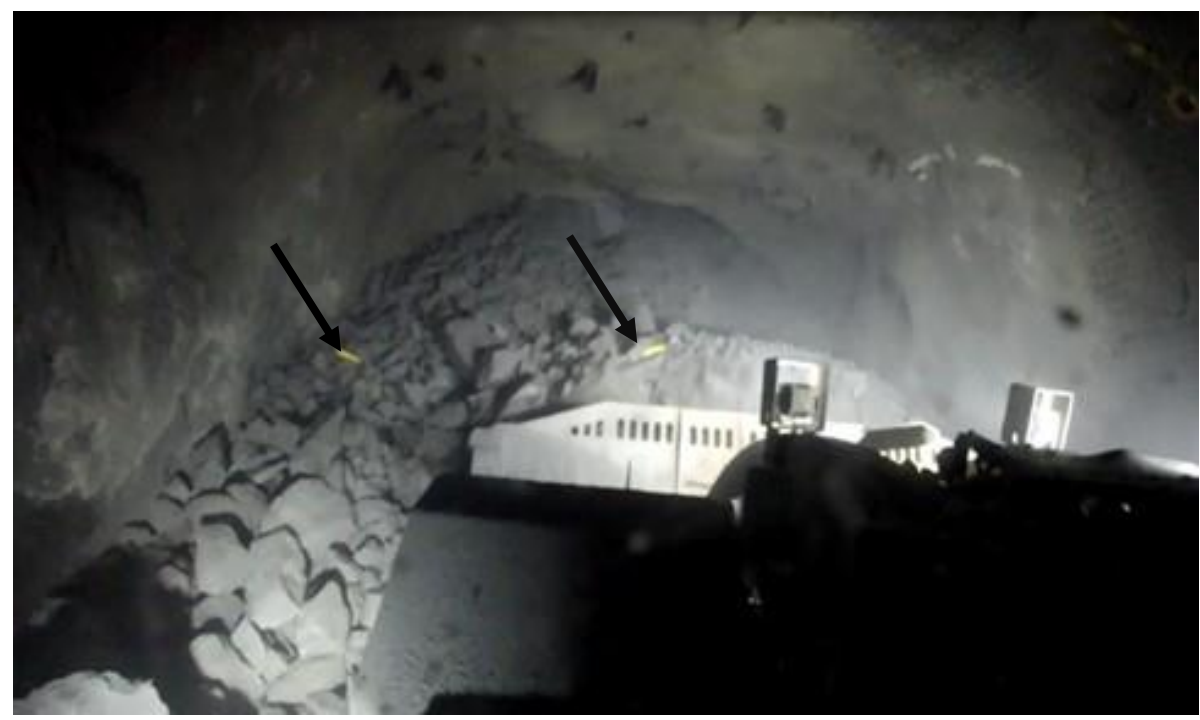

Figure 9 Visible smart markers being recovered while loading from a test ring

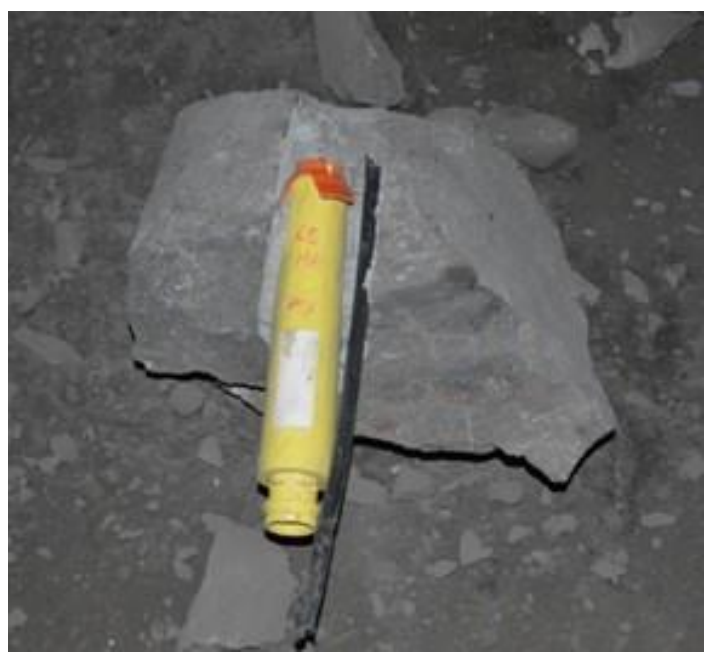

Figure 10 Smart marker recovered from a drawpoint 
Recovered markers are classified into recovery classes. These are 'primary' recovery in which markers are recovered on the same level as the blasted ring, and 'secondary' and 'tertiary' recovery, which are designated to markers recovered on subsequent sublevels. 'Backbreak' is the classification given to markers recovered by a blast ring that overbreaks into the proceeding ring. The draw zone for each recovery classification was then interpolated into volumes constrained by the ring geometry using Leapfrog ${ }^{\circledR}$ software (ARANZ Geo Limited 2018). The volume of each recovery class was then used to calculate recovery as a percentage of the blasted ring volume. The ring draw for each of the experimental blast rings was $140 \%(+/-5 \%)$.

\section{Experimental results}

Total marker recovery was calculated for all recovered markers, including backbreak recovery. Recovery in each marker plane was approximated by the ratio of marker recovered to the number of markers installed. The recovery volumes were calculated using interpolations in Leapfrog. Recovery volumes were created for each ring for each recovery type, such as primary and secondary. Interpolations were modelled using guide points created using the installation coordinate of each marker and the time, tonnage and sublevel at which each individual marker was recovered. The blast ring geometry was used to constrain interpolations. The lower boundary of the interpolation was set $1 \mathrm{~m}$ above the top of the crosscut as no markers were installed in the bottom $2 \mathrm{~m}$ of the experimental rings. An example of markers recovered in a test ring is shown in Figure 11 and interpolation of recovery volumes for Trial Programs 1 and 2 shown in Figure 12. Marker recovery results are provided in Table 2 and plotted in Figure 13. The results for each individual marker plane are provided as the ratio of marker recovery to the number of markers installed in that plane. The recovery volume is the percentage recovered in the interpolation as a proportion of the total ring volume.

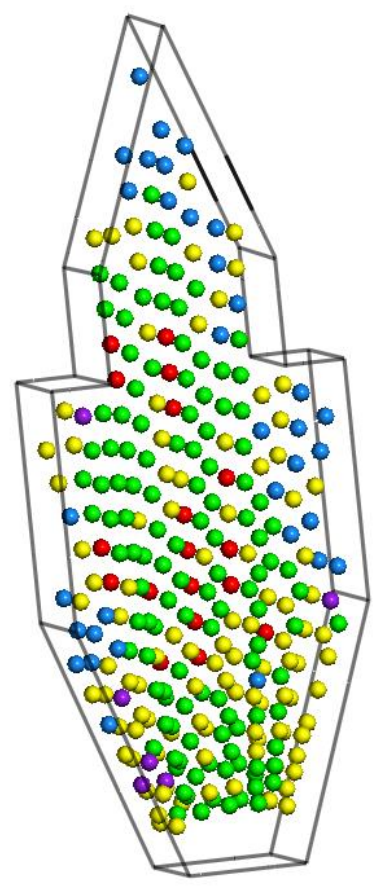

(a)

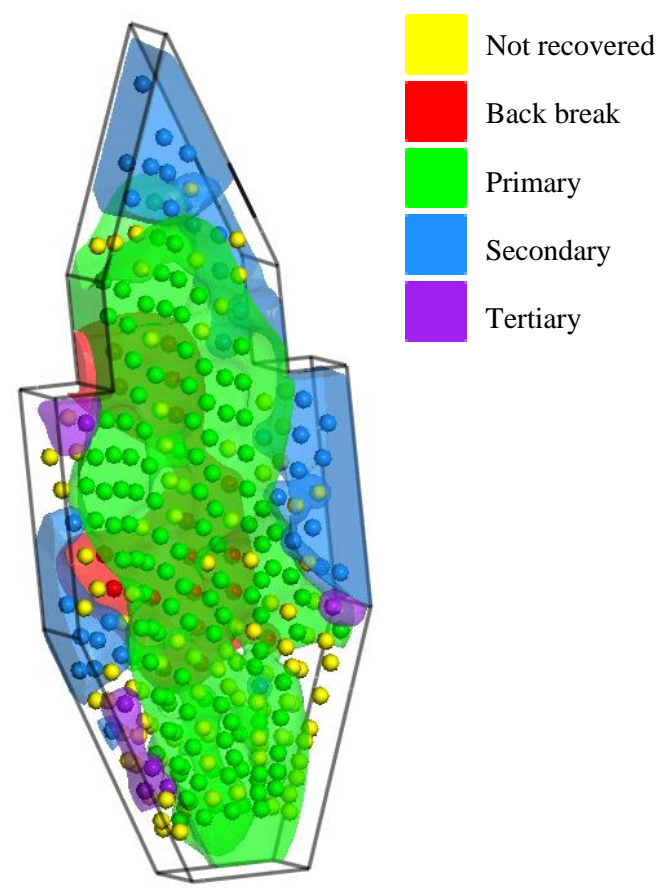

(b)

Figure 11 (a) Marker recovery by recovery class for a single blast ring; and, (b) Marker recovery volume 


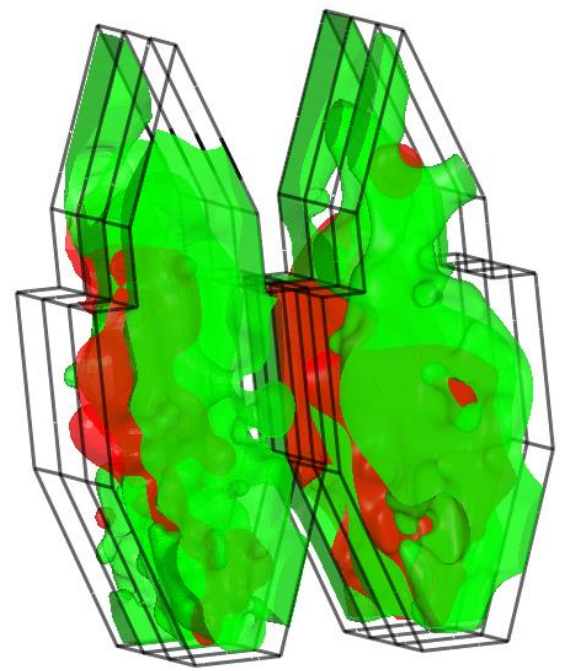

(a)

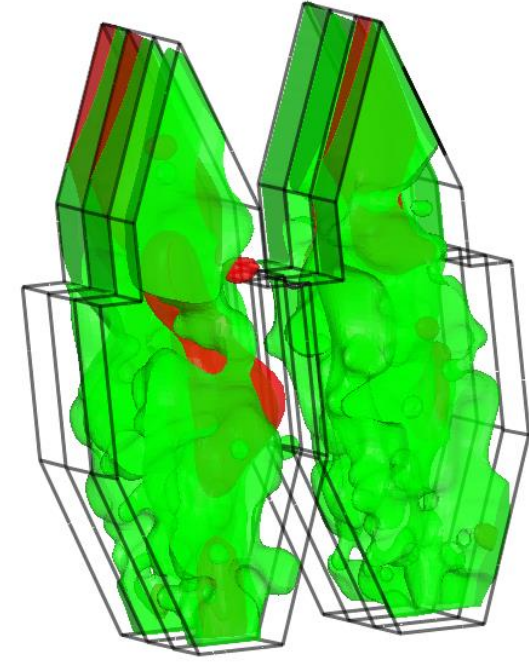

(b)

Figure 12 Recovery volumes for (a) Trial Program 1; and, (b) Trial Program 2. Backbreak in red and primary in green

Table 2 Marker recovery results (primary recovery including backbreak)

\begin{tabular}{|c|c|c|c|c|c|}
\hline \multirow{3}{*}{ Trial Program 1} & Trial ring & $\begin{array}{l}\text { Back ring } \\
\text { recovery } \\
\text { (by count) }\end{array}$ & $\begin{array}{l}\text { Centre ring } \\
\text { recovery (by } \\
\text { count) }\end{array}$ & $\begin{array}{l}\text { Front ring } \\
\text { recovery } \\
\text { (by count) }\end{array}$ & $\begin{array}{l}\text { Total recovery } \\
\text { (by volume) }\end{array}$ \\
\hline & XC9 R38 & $59.0 \%$ & $75.8 \%$ & $72.1 \%$ & $69.0 \%$ \\
\hline & XC9 R39 & $60.1 \%$ & $36.4 \%$ & $56.6 \%$ & $55.6 \%$ \\
\hline \multirow{6}{*}{$\begin{array}{l}5 \mathrm{~m} \text { crosscut } \\
\text { height }\end{array}$} & XC9 R40 & $47.0 \%$ & $53.4 \%$ & $53.3 \%$ & $53.6 \%$ \\
\hline & XC11 R38 & $37.0 \%$ & $54.2 \%$ & $44.1 \%$ & $44.7 \%$ \\
\hline & XC11 R39 & $48.9 \%$ & $42.5 \%$ & $54.7 \%$ & $49.1 \%$ \\
\hline & XC11 R40 & $48.7 \%$ & $54.4 \%$ & $61.7 \%$ & $56.2 \%$ \\
\hline & Mean & $50.1 \%$ & $52.8 \%$ & $57.1 \%$ & $54.7 \%$ \\
\hline & SD & 8.5 & 13.5 & 9.3 & 8.3 \\
\hline \multirow[t]{2}{*}{ Trial Program 2} & XC11 R67 & $49.6 \%$ & $60.5 \%$ & $50.7 \%$ & $53.8 \%$ \\
\hline & XC11 R68 & $45.9 \%$ & $64.7 \%$ & $53.7 \%$ & $52.6 \%$ \\
\hline \multirow{6}{*}{$\begin{array}{l}4 \mathrm{~m} \text { crosscut } \\
\text { height }\end{array}$} & XC11 R69 & $50.5 \%$ & $59.9 \%$ & $49.1 \%$ & $52.3 \%$ \\
\hline & XC13 R67 & $53.5 \%$ & $70.5 \%$ & $61.9 \%$ & $61.7 \%$ \\
\hline & XC13 R68 & $39.2 \%$ & $42.6 \%$ & $62.0 \%$ & $51.2 \%$ \\
\hline & XC13 R69 & $26.9 \%$ & $37.1 \%$ & $51.5 \%$ & $38.2 \%$ \\
\hline & Mean & $44.2 \%$ & $55.9 \%$ & $54.8 \%$ & $51.6 \%$ \\
\hline & SD & 9.8 & 13.1 & 5.7 & 7.6 \\
\hline
\end{tabular}




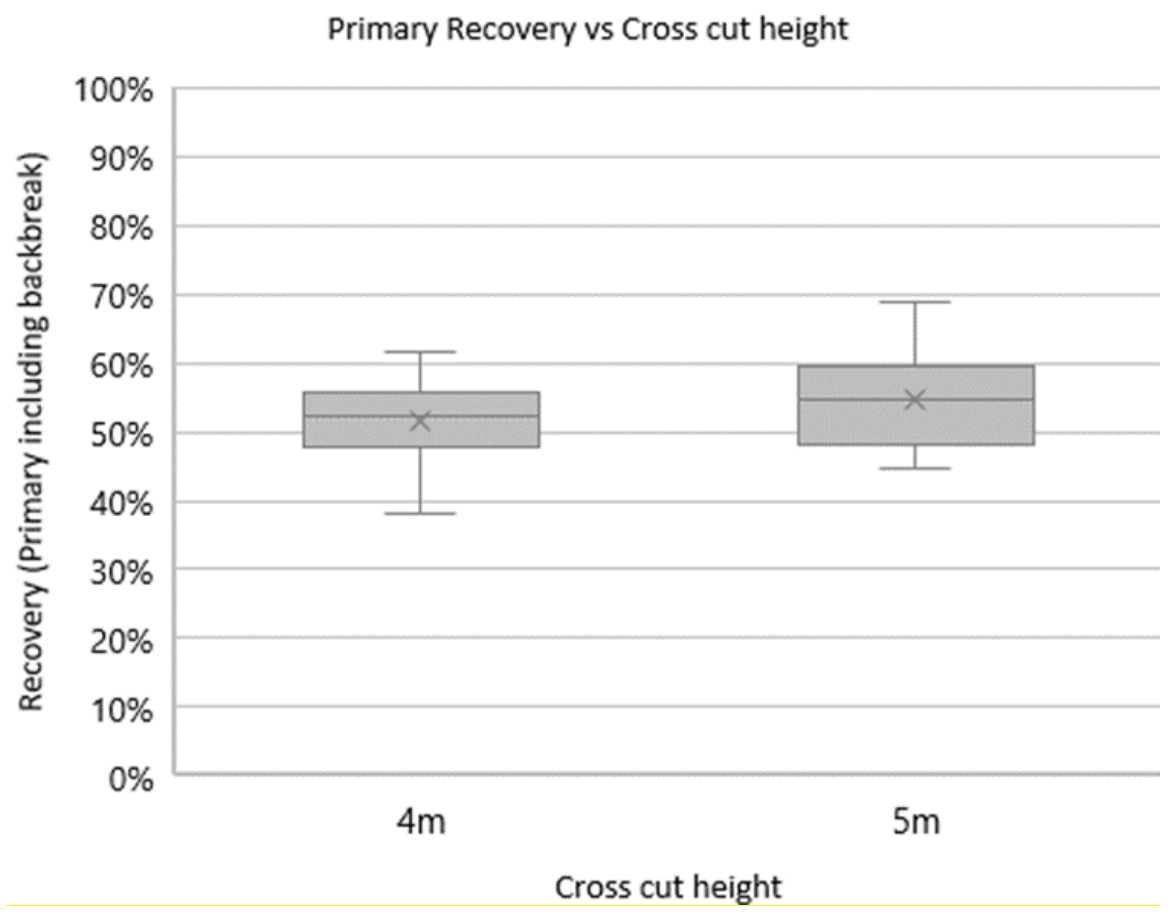

Figure 13 Box plot of the recovery results for the 4 and $5 \mathrm{~m}$ crosscut height experiments

The average total recovery (primary recovery and backbreak recovery) was measured at 54.7 and $51.6 \%$ respectively for the 5 and $4 \mathrm{~m}$ crosscut heights. Although it was hypothesised that decreasing the crosscut height by $20 \%$ would have a positive effect on recovery, it was found that the reduced crosscut height resulted in a decrease of 3.1\%. However, there was no evidence for a significant difference in group means (Student's two-sample t-test, $p=0.5138$ ). For this reason, altering the crosscut height for the secondary recovery level of Trial Program 2 was not completed and normal crosscut height and blast design parameters were implemented. As the results for Trial Programs 1 and 2 were not significantly different, they were amalgamated into a single baseline dataset for the comparison with the ring burden and explosive density trials which are detailed in a separate paper in the proceedings (Caving 2018).

It was found that recovery from the back of the ring was not increased by the reduced crosscut height as hypothesised. Recovery from the back of the ring (furthest from the drawpoint brow) was approximately $6 \%$ less when the crosscut height was reduced. While the experimental results were surprising, there is a plausible explanation. It is thought that the reduction in crosscut height did not have a positive effect on recovery as the increase in dig depth relative to the drawpoint brow was not sufficient for the bucket to reach beyond the drawpoint brow. As a result, the dig depth relative to the drawpoint brow did not affect the depth of the extraction zone.
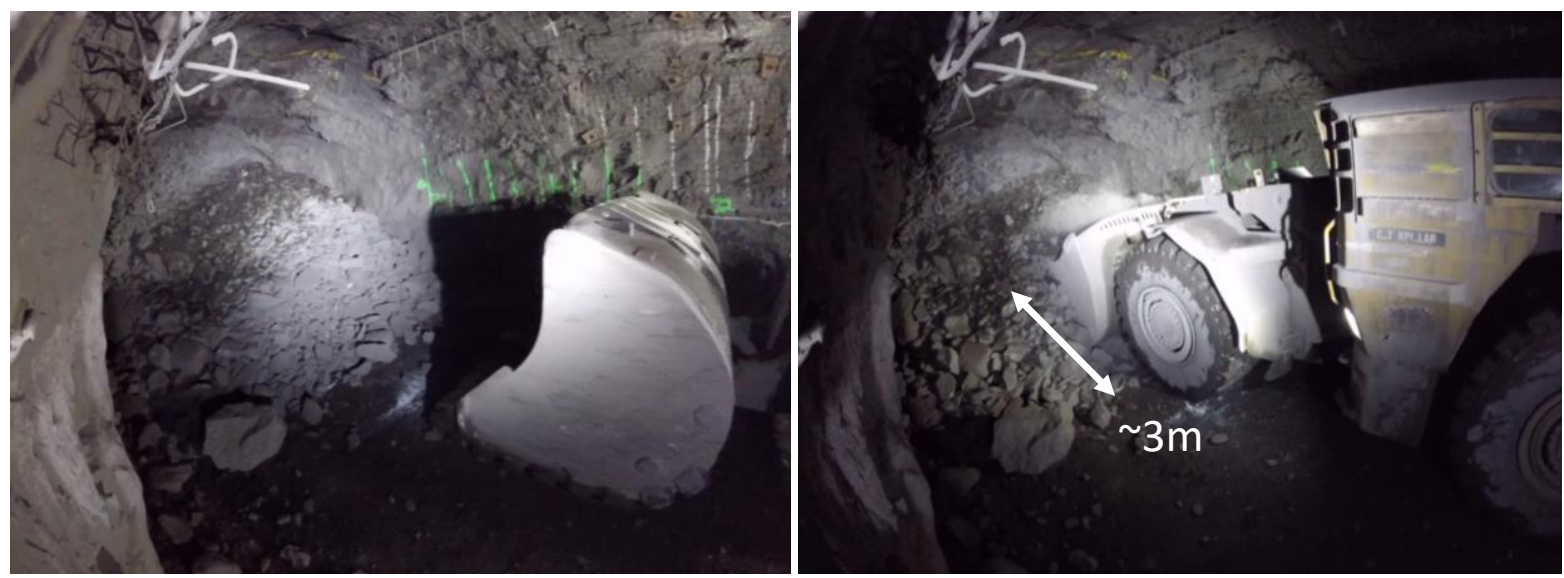

Figure 14 Example of digging depth during drawpoint loading in crosscut with reduced height 
Kvapil (1998) outlined that the digging depth of a loading machine is generally 1-1.3 m. However, measurements taken underground (using surveyed paint lines marked on the crosscut walls and video footage) showed that the actual digging depth with modern LHD equipment is generally 2-3 $\mathrm{m}$ (Figure 14). Laser scanning of the drawpoints showed that the angle of the muck pile was generally $35-40^{\circ}$. Assuming a $40^{\circ}$ muck pile, the outflow distance for a $4 \mathrm{~m}$ high crosscut is $4.7 \mathrm{~m}$, and $6 \mathrm{~m}$ long for a $5 \mathrm{~m}$ high crosscut (Figure 1). The maximum dig depth from drawpoint observations was approximately $3 \mathrm{~m}$, which is significantly less than the muck pile length for both crosscut heights tested. Therefore, the increase in dig depth was not effective at increasing recovery because the LHD bucket does not pass beyond the drawpoint brow. It is also not possible with current mining equipment to reduce the crosscut height so the dig depth is greater than the muck pile length and the bucket lip is not able to penetrate beyond the brow to potentially increase recovery from the back of a ring.

\section{$4 \quad$ Recommendations}

Results of the full-scale experiments demonstrate that a reduction in crosscut height did not achieve the desired effect of improving primary ore recovery from the back of a blast ring in an SLC mine within practical design constraints. It is recommended to conduct additional marker experiments to determine (and quantify) the effect of ring burden on primary recovery. It was postulated by both Just (1972) and Power (2004) that a reduction in ring burden may increase primary recovery. The higher ore recovery would need to offset the increased drill and blast costs associated with reducing the ring burden to increase mine revenue.

It is recommended that future SLC recovery experiments measure fragmentation at regular intervals during ore exaction and associate this with marker recovery to potentially identify different flow mechanisms and quantify the effect of fragmentation on ore recovery and outflow depth around the drawpoint brow.

\section{Conclusion}

Reducing crosscut height was hypothesised in previous SLC flow studies as a potential means to improve primary recovery. Full-scale experiments conducted at EHM found that reducing crosscut height did not have a significant or positive effect on recovery. Therefore, it does not seem justifiable that SLC mines reduce crosscut height to improve recovery from the experimental results. The crosscut height should only be reduced to improve access to blasthole collars, meet equipment requirements or improve geotechnical stability. It is postulated that the depth of draw is not controlled by the dig depth or muck pile length, but by the outflow depth or thickness of mobilised material that flows around the brow from a drawpoint. It is also thought that the outflow depth is a function of fragmentation size and that larger rock fragments result in a deeper outflow depth which may result in a larger extraction zone and higher recovery, provided the fragments are not so large as to cause blockages or hang-ups. An investigation in an operating mine is required to test this theory.

\section{References}

ARANZ Geo Limited 2018, Leapfrog Geo, computer software, ARANZ Geo Limited, Christchurch, http://www.leapfrog3d.com/products/leapfrog-geo

Brunton, I 2009, The Impact of Blasting on Sublevel Caving Flow Behaviour and Recovery, PhD thesis, The University of Queensland, Brisbane.

Brunton, I, Fraser, SJ, Hodgkinson, JH \& Stewart, PC 2010, 'Parameters influencing full scale sublevel caving material recovery at the Ridgeway gold mine', International Journal of Rock Mechanics and Mining Sciences, vol. 47, no. 4, pp. 647-56.

Bull, G \& Page, CH 2000, 'Sublevel caving-today's dependable low-cost 'ore factory", in G Chitombo (ed.) Proceedings of MassMin 2000, The Australasian Institute of Mining and Metallurgy, Melbourne, pp. 537-556.

Campbell, AD 2018, 'Effects of blast ring burden and explosive density on fragmentation and ore recovery in sublevel cave mines', in Y Potvin \& J Jakubec (eds), Proceedings of the Fourth International Symposium on Block and Sublevel Caving, Australian Centre for Geomechanics, Perth, pp.485-498.

Campbell, AD \& Power, GR 2017, 'Improving calibration of flow models against SLC marker trials by linking blasting effects to particle mobility', Proceedings of the 13th AusIMM Underground Operators' Conference, The Australasian Institute of Mining and Metallurgy, Melbourne, pp. 11-22. 
Dunstan, G \& Power, G 2011, 'Sub level caving', in P Darling (ed.), SME Mining Engineering Handbook, 3rd edn, Society for Mining, Metallurgy, and Exploration, Englewood.

Elexon Mining 2017, Smart Marker System, apparatus, Elexon Mining, Brendale, viewed 20 May 2017, https://www.elexonmining.com/smart-marker-system-3

Gustafsson, P 1998, Waste Rock Content Variations During Gravity Flow in Sublevel Caving: Analysis of Full-scale Experiments and Numerical Simulations, PhD thesis, Luleå University of Technology, Luleå.

Hollins, B \& Tucker, J 2004, 'Draw point analysis using a marker trial at the Perseverance Nickel Mine, Leinster, Western Australia', in A Karzulovic \& M Alfaro (eds), Proceedings of MassMin 2004, Instituto de Ingenieros de Chile, Santiago, pp. $498-502$.

Just, GD 1972, 'Sublevel caving mining design principles', Institution of Mining and Metallurgy Section A, October, pp. A214-A220.

Kosowan, MI 1999, Design and Operational Issues for Increasing Sublevel Cave Intervals at Stobie Mine, MSc thesis, Laurentian University, Sudbury, p. 152.

Kvapil, R 1998, 'Mechanics and design of sublevel caving systems', in RE Gertsch \& RL Bullock (eds), Techniques in Underground Mining, Society for Mining Metallurgy and Exploration, Englewood, p. 621.

Page, CH \& Bull, G 2001, 'Sublevel caving: a fresh look at this bulk mining method', in WA Hustrulid \& RL Bullock (eds), Underground Mining Methods: Engineering Fundamentals and International Case Studies, Society for Mining, Metallurgy, and Exploration, Englewood, pp. 385-394.

Power, GR 2004, Modelling Granular Flow in Caving Mines: Large Scale Physical Modelling and Full Scale Experiments, PhD thesis, The University of Queensland, Brisbane.

Quinteiro, CR, Larsson, L \& Hustrulid, WA, 2001, 'Theory and practise of very large scale sublevel caving', in WA Hustrulid \& RL Bullock (eds), Underground Mining Methods: Engineering Fundamentals and International Case Studies, Society for Mining, Metallurgy, and Exploration, Englewood, pp. 381-384.

Trotter, DA \& Goddard, GJ 1981, 'Design techniques for sublevel caving layouts', Canadian Institute of Mining Bulletin, January 1981, pp. 92-100.

Wimmer, M 2010, 'Gravity flow of broken rock in SLC - the state of the art', Swebrec Report 2010:P1, Luleå University of Technology, Luleå.

Wimmer, M 2012, Towards Understanding Breakage and Flow in Sublevel Caving, PhD thesis, Luleå University of Technology, Luleå.

Zhang, G 2004, 'Behaviour of caved ore mass in sublevel caving and its effect on ore dilution', in A Karzulovic and M Alfaro (eds), Proceedings of MassMin 2004, Instituto de Ingenieros de Chile, Santiago, pp. 238-242. 
